\title{
Policy and objectives of the New Zealand Arthropod Collection
}

\author{
Darren F. Ward ${ }^{\ddagger}$, Sarah M. Tassell \\ ‡ Manaaki Whenua - Landcare Research, Auckland, New Zealand
}

\section{Abstract}

The New Zealand Arthropod Collection (NZAC) is the world's largest taxonomic collection of terrestrial invertebrates from New Zealand. The NZAC policy is presented that defines the vision for the collection of being managed to the highest international standards, connected through a global infrastructure, and providing high quality, authoritative, and trusted information. The policy also provides context and guidelines for collection activities, and twenty-two objectives are outlined that will be completed over the next 5 years.

\section{Keywords}

collection management, entomology, invertebrates, natural history collections, policy, strategy

\section{Introduction and Background}

The New Zealand Arthropod Collection (NZAC) is the world's largest taxonomic collection of terrestrial invertebrates from New Zealand. Ownership of the NZAC is currently vested in Manaaki Whenua - Landcare Research (MWLR) a government Crown Research Institute. The NZAC is one of five Nationally Significant Collection and Databases managed by MWLR focusing on taxonomy, systematics, and natural sciences. The NZAC is research 
collection that is maintained on behalf of all New Zealanders as an important scientific asset to support research, science, and technology outcomes (Hodgson 2008).

The collection was started in 1920 as the Cawthron Institute collection in Nelson, but was moved to Auckland in 1973, where is it currently based. The NZAC contains approximately 1.6 million collection "objects", and together these objects contain an estimated 7 million individual specimens, primarily from New Zealand but also from neighbouring Pacific Island Countries. There are approximately $1,250,000$ dry mounted specimens (pins); 250,000 fluid specimen lots (e.g., jars, vials, including bulk samples); 100,000 microscope slides; and 6,000 dried plant specimens (as sheets and envelopes, kept as vouchers of plantinvertebrate associations and invertebrate damage). Twenty thousand new objects are added each year (5-year average).

Approximately $12 \%$ of the objects in the collection have been digitised (>202,000 records as of April 2021) and are publicly available via the institutional Systematics Collections Data portal and the Global Biodiversity Information Facility GBIF (NZAC-GBIF 2021). An average of twenty thousand new specimen records are digitised each year (5-year average, as a mix of newly acquired and backlog material). There is also have a dedicated molecular collection, and the contents can be searched via the Global Genome Biodiversity Network (GBBN) portal.

The NZAC currently has six researchers, who also act as curators for certain taxonomic groups, and four technical staff (including a Collection Manager). Taxa of current research focus are Coleoptera (beetles), Lepidoptera (butterflies and moths), Hymenoptera (parasitoid wasps), Phasmids (stick insects), Acari (mites), and Nematoda (plant parasitic nematodes). Hemiptera (all suborders) have also been well researched, and the collection holdings are highly curated and digitised. Several research associates also contribute to taxonomic research and collection curation of ground beetles (Carabidae), weevils (Curculionidae) and Heteroptera (Hemiptera).

The NZAC is an important national repository for voucher specimens from ecological surveys, importations of biocontrol agents, and newly established exotic species. Significant holdings include: $>4000$ holotypes; the Maskell collection of scale insects (Hemiptera: Coccoidea), with specimens from the 1870s; the Broun duplicate collection of beetles and the Brookes beetle collection from the late 1800s and early 1900s; and specimens from early insect surveys in the 1920-1930s from the Department of Agriculture. There is also a significant collection of weevils from South America and other parts of the world originating from the Kuschel Collection purchased in 1963; and a substantial South Pacific collection held in trust for Pacific nations.

The NZAC fits into the organisational framework of MWLR (e.g., Strategy 22, and the Biota Portfolio Strategy), however, it maintains its own policy and strategy. Recently, one of us has [ST] participated in online workshops organised by iDigBio on 'Strategic Planning for Biodiversity Collections', where draft goals and objectives were developed as part of a wider collection strategy for stakeholders and administrators. This work was further augmented by internal discussions and decision-making. 
There are increasing demands on taxonomic collections staff for access and use specimens and their data (Committee on Biological Collections 2020, Lendemer et al. 2019, Miller et al. 2020) and open science practice (Mietchen et al. 2021). However, there is often little information specifically for invertebrate collections (but see Väinölä et al. 2020), and therefore hope that sharing this policy, goals, and objectives might be informative for other collections.

\section{Policy}

This document sets forth the policy statements and guidelines for the management of the New Zealand Arthropod Collection (NZAC). This document covers: i) all specimens accessioned by, or in the care of, the NZAC and ii) all specimen and transactional databases associated with the NZAC.

Any person working within or with access to NZAC facilities, or who have delegated responsibilities for the collection, is required to adhere to this policy. This includes but is not limited to all NZAC staff, research associates, students, interns, volunteers, causal wage workers, subcontractors, visiting researchers, members of the public, and staff from MWLR.

\section{Responsibilities and Compliance}

\section{Responsibilities}

The New Zealand Arthropod Collection is managed by a Head Curator, who bears ultimate responsibility for the care and curation of the collection, including execution of this policy. The Head Curator will appoint a Collection Manager from the NZAC technical staff and delegate responsibilities for taxonomic groups to Section Curators. The latter are often the first point of contact for external and internal requests, and have responsibility for day-today management of their respective taxonomic group(s). However, section curators must comply with NZAC policy and procedures, and are appointed on the understanding that the Head Curator has ultimate authority and responsibility for the NZAC. This policy is reviewed on a needs basis by the Head Curator, with input from other collection staff, and approved by the Portfolio Leader.

\section{Compliance}

The NZAC will comply with all applicable internal MWLR standard operating procedures and strategies, and all applicable New Zealand and international legislation, including: the Treaty of Waitangi 1840; the New Zealand Wildlife Act (1953); the Convention for International Trade in Endangered species (CITES); the Protected Objects Act (1975, updated 2006); the Reserves Act 1977; the National Parks Act 1980; the Official Information Act 1982; the Conservation Act 1987; the Trade in Endangered Species Act 1989; the Convention on Biological Diversity 1992; the Crown Research Institutes Act 1992; the Biosecurity Act 1993; the Privacy Act 1993; the Hazardous Substances and New 
Organisms Act 1996; the Public Records Act 2005; the Antarctic Treaty 1961; Ministry for Business, Innovation and Employment policy/initiatives (e.g., Principles for Managing Publicly-Funded Environmental Data, eResearch, Vision Mātauranga).

\section{Collection Management and Maintenance}

Collection Management refers to the responsibility and function of an institution to foster the preservation, accessibility, and utility of the collection and associated data (SPHNC. 2021). Ultimately the accessibility and value of a collection depends on the systematic organisation of the specimens and data (Väinölä et al. 2020).

The long-term preservation and protection of both specimens and documentation in the NZAC is paramount. This requires specialised methods for storage, pest control, specimen handling and the security of the collection facilities. To ensure this:

- Collection management shall be consistent with the best available information (including disaster preparedness, preservation techniques, assess and use, regulations, informatics, etc.).

- The physical conditions of the NZAC facilities and environs will be maintained to international best practice standards for natural history collections (including protection against fire, moisture, pest infestation, and other hazards).

- Storage hardware/units and packing materials will be of archival quality

- Materials used for specimen preparation and curation will be of archival quality

- $\quad$ Primary type specimens will be housed in separate secure cabinets within the main collection vaults.

\section{Collection Organisation}

The organisation of the collections and specimens is aimed at ease of access and is typically arranged taxonomically.

All material types (pinned, slides, fluid vials, dried specimens) are generally organised by taxonomic order (Coleoptera, Diptera, Hemiptera, Hymenoptera, Lepidoptera), subclass (Acari) or Phylum (Nematoda). For pinned material, other insect orders are kept in a 'Small Orders' section but each order is separate; and Curculionoidea are separated from Coleoptera due to space limitations. Further organisation is at the discretion of the Section Curator, but it is broadly phylogenetically based, and then with family, genus, and species levels arranged in alphabetical order. Unsorted material is kept at the end of each order or family.

Specimens that are not from New Zealand are typically kept at the end of each order or family. The voucher collection of biological control agents is stored separately. Bulk samples are often stored by project or by geographic area. At the highest level of taxonomic organisation, it is best practice to store the specimens by the New Zealand area code ("Crosby code") (Crosby et al. 1998). Wherever possible, accessioned specimens 
within a species should be filed in order of their accession number from lowest to highest so that it is easy to locate specimens.

- Specimens that are pinned, slide-mounted, in envelopes, and dried plant specimens are kept in two facilities (the Tillyard vault and the Kuschel vault). The ambient conditions in these vaults are monitored and adjusted for the optimal preservation of the collections. Vaults are kept at $18 \mathrm{C}$ degrees and approximately $50 \% \mathrm{RH}$, to minimise pest risks. Vaults are without windows and fire protection is provided by an inert gas flooding system (Prolnert).

- $\quad$ Pinned specimens are kept in glass-topped Cornell-sized wooden drawers in cabinets.

- $\quad$ Slide-mounted material is stored on metal 'slide-out' trays within custom-built wooden boxes (max. 400 slides per box).

- $\quad$ Dried plant material is either fixed onto paper sheets or placed within envelopes (e.g., galls, flowers), and both are stored in herbarium boxes.

- $\quad$ Specimens stored in fluid (e.g., ethanol, formalin) are kept in two cool stores which are outside and adjacent to the main collection and kept darkened at $6 \mathrm{C}$ degrees.

- $\quad$ Frozen specimens that are kept for molecular work are stored either in -20C freezer or a $-80 \mathrm{C}$ ultracold freezer.

\section{Collection Care}

Collections staff and building site management monitor the ambient conditions in the collection facilities. Potential occurrence of pest insects in the collection facilities is regularly monitored using 'blunder' sticky traps in vaults and laboratory facilities. Fumigation of the two vaults is undertaken every $\sim 3$ years, and currently used only as a preventive measure. The condition of fluid-preserved samples is monitored and 'topped up' on an ad hoc basis.

\section{Curatorial Standards}

The guiding principles for the management of the NZAC are:

- To always maintain the physical safety of specimens.

- Quality has priority over quantity.

- Ensure specimens and associated data are maintained to high international curatorial standards.

- Insofar as possible, focus activity on specimens and taxa of priority to key users.

- $\quad$ Provide open access to information and data deriving from the NZAC.

The procedures of curation and for preparing various specimen types are undertaken by Section Curators and technical staff based on their expertise and experience, although basic practices are recorded in (Walker and Crosby 1988). 


\section{Documentation and databases}

Documentation and data associated with the NZAC includes field notebooks, notes accumulated by researchers, collection management documents, and electronic databases.

NZAC staff, research associates, and visitors, must exercise the same duty of preservation and protection towards collection documentation as towards physical specimens. As such, material and documents cannot be disposed of without assessment from the Collection Manager and Head Curator and are digitally archived where possible.

Specific collection procedures will be developed and maintained by the Head Curator and/ or delegated staff. Section Curators are responsible for maintaining information on the whereabouts, and ensuring the safety, of collection documentation associated with the invertebrate groups under their care. Relevant information is to be passed on when new staff are appointed to the positions of Section Curators or Head Curator. All documents relating to the management of the NZAC will be maintained in permanent shared online space.

\section{Acquisitions}

\section{Acquisitions}

The NZAC is an active collection; specimens are added each year through field work by staff associated students, adjunct staff, and visitors, through the deposition of vouchers, and less often from donations, bequests, exchanges, purchases, and gifts.

In general, for specimens donated to the NZAC, all IP rights will be transferred to MWLR to ensure that IP is available to those accessing the NZAC. Nonetheless, this policy is designed to protect the rights under the Treaty of Waitangi of Māori, as expressed through their traditional iwi, hapū and whanau structures, recognising that iwi, hapū or whanau exercise manawhenua over the collecting locality.

All specimens acquired by the NZAC are subject to the policies and procedures of the NZAC.

Additions to the NZAC shall be made with due consideration to the scientific value, quality of specimens and associated labels/data. The capacity of staff to curate material and physical space for storage must also be considered.

- Specimens must be of good quality to be approved for acquisition. Associated data should at a minimum include provenance, the date collected, and the collector.

- While NZAC, as a nationally significant collection, is a major repository of voucher material for non-taxonomic research (e.g., ecological studies, biological control introductions, DNA vouchers etc.), inadequately prepared or poorly documented material will not be accepted. 
- $\quad$ For large acquisitions, the Section Curator must work with the Head Curator to complete an assessment of the acquisition including its significance, quality as well as capacity of NZAC; prior to decision to accept or reject.

- Large quantities of material may incur a charge to cover the excess staff time required to sort and process the material during accessioning.

- Unprocessed 'bulk' samples may be accepted, if samples are in good condition and are: i) are individually labelled (with a minimum of provenance, the date collected, and the collector), and preferably ii) metadata for each sample is also provided in electronic form.

No specimens will be accepted that have been collected in contravention of any current international law or conventions, or in contravention of any New Zealand Government laws or regulations, unless the donor is a legal New Zealand authority.

Contributors/donors will be required to declare that they are legally entitled to deposit the specimens and give the NZAC the right to use the specimens and associated data. Copies of collecting or other related permits, agreements with landowners, and all relevant extracts of each permit, must be provided when specimens are deposited. Due diligence by the NZAC must be demonstrated and associated documents (e.g., permits and written agreements with landowners) must be kept in permanent record systems.

\section{Donations and Bequests}

NZAC encourages the donation and bequeathing of specimens, provided they meet the objectives and the guiding principles of the NZAC. Accepting these is at the discretion of the relevant Section Curator in conjunction with the Head Curator.

- Donations and bequests require a material transfer agreement (MTA).

- The section curator is responsible for ensuring that all paperwork associated with donations and bequests is completed to policy standard and lodged in electronic storage. Section curators are also responsible for arrangements for receipt of specimens into NZAC and ensuring that NZAC procedures are followed (e.g., pest management requirements, or return of boxes or cabinets to donors).

- $\quad$ The Section Curator will work with the Head Curator and Collection Manager to ensure that NZAC procedures for processing new acquisitions are met.

Donations and bequests will be rejected if they come with attached conditions (e.g., those specimens are kept separate from the main collection), or where it cannot be demonstrated that specimens were obtained legally.

Specimens later deemed of poor quality or not meeting the NZAC's curatorial criteria will be disposed of as per the deaccessioning procedures.

\section{Exchanges and Gifts}

NZAC encourages a cautious policy of exchanging specimens with other legitimate research institutions to obtain material of species poorly or not represented in its collection, 
while parting with material of well represented species. This also helps 'spread the risk' to specimens in the event of a disaster affecting either the NZAC or a partner institution.

- Exchange and gifting of specimens is at the discretion of the relevant Section Curator in negotiation with the Head Curator. Details should be documented, and records maintained by the Section Curator.

- Gifts of specimens to other institutions (from the NZAC without exchange) may be considered if the NZAC holds large numbers of duplicate specimens of a species.

- $\quad$ 'Gift' specimens sent oversees may be subject to import (and potentially export) fees in some countries as gifts are not covered under the exemption from import/ export fees for exchange of scientific specimens in some jurisdictions. NZAC will not cover the cost of such fees.

- $\quad$ Cataloged specimens (i.e., those with NZAC accession numbers) may only be exchanged or gifted if their digital records are updated. A transaction record for the transfer or gifting must be created within the Transactions module of CIS.

The following categories of specimens will not be exchanged or gifted:

- $\quad$ Primary type specimens.

- $\quad$ Other type material for which the NZAC is already the published repository.

- Specimens deemed of historical importance.

- $\quad$ Specimens of species known to be extinct or endangered.

- Specimens with permit conditions that do not allow for the transfer of material from NZAC to other institutions or transfer of ownership to entity outside of New Zealand.

\section{Accessioning and Deaccessioning}

The NZAC is committed to maintaining a comprehensive, well prepared, and usable collection. These aims are chiefly met by accession of new material and the continued preservation and curation of current holdings. However, while maintaining a high standard of curation and conducting scientific research there will be the occasional need to damage, dispose of, or destroy, certain specimens.

\section{Accessioning}

Accessioning is the process used to legally acquire and record an object(s) by creating a permanent digital record (e.g., of specimens or samples into the collection). All specimens accessioned into the NZAC will be databased and given a unique NZAC accession number. Material held by the collection belongs to the collection even if it has not been digitally registered (accessioned).

From 2020 onwards, it is policy to accession all new incoming specimens and samples. This is part of a digitisation strategy to reduce the backlog of specimens requiring future databasing. 
At a general level, specimens to be accessioned are prioritised as follows:

- Scientifically valuable and technically high-quality specimens.

- Specimens which augment existing holdings (e.g., represent missing developmental stages, expand time series, or broaden the geographical or taxonomic scope).

- Specimens with no immediate research value, but which may be useful for education or the public outreach of biodiversity.

\section{Deaccessioning}

Deaccessioning is the formal process used to remove a specimen permanently from the collection (e.g., by gifting, exchanging, transferring, or disposing of accessioned specimens; SPHNC. 2021). Disposing of accessioned specimens should be limited to specimens that are damaged beyond repair (e.g., by pests, mould or grease, mishandling, or corrosion of the pin), are very poorly prepared, or unlabeled.

- $\quad$ Specimens with existing images and/or DNA should not be deaccessioned.

- Type specimens and historical specimens cannot be deaccessioned.

\section{Destructive sampling and molecular analysis}

Destructive sampling, whether conducted either in the NZAC environs or for specimens on loan, may be conducted for: i) morphological study, where parts are removed from a specimen (e.g., dissection of body parts, slide mounting or SEM); or ii) molecular study, where the whole specimen, or part of the specimen, may be destroyed.

Requests to destructively sample specimens must be made as part of a loan request. The conditions will be outlined in the loan agreement form which must be signed by the requester and returned to NZAC before specimens are dispatched.

Approval will be given by the Section Curator or Head Curator who will consider the following criteria:

- The project being undertaken and the information to be gained are important enough to warrant the resulting damage to the specimen and potential risk of permanent damage during destructive sampling.

- $\quad$ The need for the NZAC material to help with the project.

- The ability of the borrower (for specimens on loan) to perform the sampling without unnecessary damage to specimens.

- $\quad$ Any permit and usage obligations have been met.

The NZAC retains the right to refuse approval for destructive sampling of its specimens.

- $\quad$ Type specimens and historical specimens are not eligible for destructive sampling where the whole specimen is required.

- At all times, the principle of minimal damage to the specimen (and especially to parts that are important for morphological studies) is to be followed. 
- Where destruction of a whole specimen is required, specimens chosen should be from a long series of duplicates.

NZAC specimens will only be loaned for destructive sampling under the following process:

- The borrower must first receive approval before performing any destructive sampling. Approval is given by the Section Curator or Head Curator.

- The borrower must deposit all DNA sequences obtained from NZAC specimens in an internationally recognised DNA database (e.g., GenBank, BOLD).

- $\quad$ The borrower must attach NZAC accession numbers (which we can provide) to specimens to link physical specimens with databased information and publications.

- Any associated numbers associated with DNA sequences (e.g., lab codes, Genbank numbers) should be sent to the NZAC loans officer to update specimen records.

- $\quad$ The borrower must acknowledge the use of NZAC specimens in any resulting publications. Accession numbers for type specimen must be listed in the publication. For non-type material, accession numbers for any material that is used examined should be listed within the paper or as an appendix or dataset.

Tissue or other components of the specimen removed during destructive sampling are not to be passed to third parties without written permission of the Head Curator.

\section{Access and Use}

\section{Access}

Visits to the NZAC are available to bona fide researchers for taxonomic and/or associated invertebrate research ('non-taxonomic research').

Authorisation to use the Collection is required for all visitors. Access will be by written appointment to the Section Curator, or if unavailable, the Head Curator.

Visitor access is available Monday-Friday between $9 a \mathrm{~m}-4.30 \mathrm{pm}$. Access outside these times needs additional approval from the Section Curator or Head Curator.

A record is kept on visitors working with the collections. The person overseeing the visit ('the host') is ultimately responsible for the visitor being familiar with both the appropriate procedures of handling scientific specimens and with related health and safety matters.

\section{Use of the NZAC}

All visitors will be given an induction covering health and safety issues and the appropriate use of NZAC specimens and facilities, and are required to sign an agreement declaration.

- $\quad$ NZAC staff may monitor visitors to ensure the safe handling and security of specimens, data access, and the appropriate use of facilities.

- Visitors will be denied access to, and/or asked to leave, facilities, if rules are not complied with 
Access may be restricted or denied to certain data or specimens; for example, holotypes, specimens that are unusually fragile, or currently under research by NZAC staff.

Visitors must obtain written approval from the Section Curator prior to photographing, annotating labels, dissecting any part of a specimen, or removing any part of a specimen for molecular analyses. Wherever possible, links to images, sequence data, and other outputs of research on each specimen should be provided to the Head Curator or Collection Manager so that specimen records can be updated. Determination updates for material examined should also be provided so that records can be updated.

Specimens should only be examined in the collection vaults, NZAC offices, or NZAC labs. Specimens are not to be removed from the NZAC environs without approval from the Section Curator.

- Any specimens taken off-site must be prepared as a loan or transfer through the NZAC loans officer. Specimens must be packed following best practice standards, protected in transit, and provided the same level of care at the off-site location as is available in the NZAC.

- $\quad$ Removal of type material and historical specimens from the NZAC environs is not permitted unless on loan.

A bench fee may apply to visitors using the NZAC for commercial gain, including individuals working as subcontractors to other organisations. Authority to lower or waive any fees rests with the Head Curator.

No visitor can incorporate any material or specimens into the collection vaults or the ethanol room without the approval from the Section Curator or the Head Curator.

Visitors may not use the NZAC facilities for long-term storage of equipment, samples, or specimens without the approval from the Head Curator. Such items left in the NZAC facilities will be considered abandoned and subject to NZAC policy and procedures.

\section{Outgoing Loans}

Loans of specimens must conform to CITES, Biosecurity, customs, and international dangerous goods shipping regulations. The loan of type material must conform to the Protected Objects Act 2006.

All outward loans must be approved by the relevant Section Curator or the Head Curator.

Loans will only be made for NZAC specimens and will not be made for specimens belonging to other institutions that are currently on loan to the NZAC.

NZAC specimens and samples (including bulk samples) must be accessioned prior to being sent on loan. This means that loan preparation needs to include time for specimens and samples to be accessioned. 
The NZAC policies and procedures, particularly those on destructive sampling, apply to all specimens while on loan.

Loans are made to accredited institutions, rarely to individual researchers. Loans are generally made to bona fide researchers for taxonomic and systematic study. The loan period by default is 24 months, or 3 months for type specimens. The extension of loans must be made in writing.

Primary type specimens will only be loaned to researchers of unimpeachable reputation, who are unable to visit the NZAC, and unable to complete their studies without viewing the specimen(s). All international loan requests must conform to the Protected Objects Act 2006.

Type specimens that are considered too fragile to post safely or where there is unreasonable level of risk of being lost or destroyed during transport will not be approved. Specimens may be imaged at the NZAC instead.

All loans must conform to the Standard Loan Conditions, and to ensure the safety of specimens:

- Loan requests must be in writing.

- The loan request is reasonable in scope. For each taxon, not all specimens should be sent on loan at any one time. If possible, some representative specimens should remain in the NZAC. If necessary, the remaining specimens may be sent when the first batch of loan material is returned.

A loan request will be refused if:

- It is considered that the research impinges on the safety and integrity of the specimens.

- $\quad$ There is a reasonable ability to come into the NZAC and undertake the study.

- The taxon is being actively studied by NZAC staff, unless the researcher(s) gives their consent.

- It is considered excessive in scope.

- It is from an individual or institution that has previously failed to comply with the Standard Loan Conditions or is considered to have abused the loans system.

- $\quad$ Physical conditions where loaned specimens are to be stored are known not to be suitable (e.g., pest infestations)

Loans for non-taxonomic purposes (e.g., anatomical, ecological, or geographic) will be approved by the relevant Section Curator, in consultation with the Head Curator, and will be subject to the following:

- Type specimens or specimens considered to be of historical importance are not available. 
- Loans will be to the project supervisor at a recognized scholarly institution. The supervisor will be responsible for the specimens' care during the loan term and return the loan to the NZAC by the agreed date.

Use of loan specimens in projects of a commercial nature are unlikely to be approved and require separate and specific approval from the Head Curator in consultation with the senior managers at MWLR. A fee may apply to such requests.

\section{Incoming Loans}

Individual NZAC staff wishing to borrow from other institutions are responsible for:

- Submitting loan requests to the loaning institution.

- Maintaining loan records and other documentation.

- $\quad$ Providing the same standard of care for material on loan that applies to the NZAC.

- Returning loaned material by the deadline stipulated by the loaning institution or seeking an extension where necessary.

- Including the NZAC loans officer in loan communications, who will officially register the loan via the 'transactions module'.

- Complete appropriate pest quarantine process for incoming loan material

Loans from other institutions are not to be incorporated into the main NZAC collection unless each specimen is clearly labelled to indicate the originating institution.

Incoming loans for research associates, visitors, and students must be made via the relevant Section Curator or Head Curator. In such situations, the names of NZAC staff must be on the loan requests, and NZAC staff members have ultimate responsibility for the loans.

\section{Photographing specimens}

To help manage the IP of photographs, NZAC specimens will normally be photographed by members of NZAC staff. However, the NZAC typically releases photographs and images under Creative Commons licenses of CC-BY and CC-BY-SA.

Visitors with a proven track record of appropriate specimen handling may be allowed to photograph specimens at the discretion of the relevant Section Curator, and must follow the procedures below:

- Images of NZAC specimens used in publications must be duly acknowledged as the source.

- The file associated with all photographed specimens should be labelled with a standard NZAC accession number.

- Copies of images of NZAC specimens are to be lodged with the NZAC, and the NZAC will maintain joint copyright with the photographer or relevant institution.

- $\quad$ Specimens on loan may be photographed by the borrowing institution/individual only with approval. 
- Images may be used for commercial purposes only with the express approval of the Head Curator.

\section{Data and Documents}

All data relating to specimens in the NZAC shall be available for public access unless such information is confidential or relates to research in progress.

- $\quad$ Authority for withholding data lies with the Head Curator.

- A charge may be levied if access to data requires a considerable amount of staff time, or if the data is to be used for commercial purposes.

The use of any data obtained from specimens (e.g., morphological measurements, locality records, molecular sequences, images, etc.) from the NZAC is to be fully acknowledged. A copy of data captured and/or scientific papers or reports should be lodged with the NZAC.

Data may not be passed to any third party for commercial purposes without the written permission of the Head Curator.

\section{Safety and Security}

\section{Safety of staff and visitors}

All NZAC staff and visitors will follow the Landcare Research and NZAC induction procedures and be aware of safety features and evacuation procedures.

The Head Curator, in liaison with the Site Manager, will ensure purchase and maintenance of response equipment and other resources necessary to effectively respond to small and localised emergencies within the NZAC facilities. NZAC staff will be provided with training so that they are equipped to respond to an emergency within the NZAC facilities.

The Head Curator will ensure the NZAC is appropriately represented within the Auckland Site Emergency Response Plan.

\section{Security with visitors}

The long-term preservation and protection of specimens and documentation in the NZAC is paramount. To ensure this:

- The Head Curator will work with the Site Manager to ensure that appropriate security measures are in place to control access.

- Only NZAC staff members are allowed to admit visitors to the NZAC. External visitors are not permitted to host other external visitors without NZAC staff present.

- Visitor activities will be monitored, and visitors may be actively supervised.

- Groups of people in the vaults should be always supervised by a member of the NZAC staff. If groups are too large, they may be denied access, or split into smaller groups. 


\section{Volunteers}

The NZAC encourages the use of volunteers to meet objectives of the NZAC. To ensure the safety of specimens, assign appropriate IP, and manage the collection effectively:

- Volunteers are approved by the Head Curator.

- Prospective volunteers must complete a volunteer application form and once approved, must sign a volunteer assignment.

- Volunteers assist in various activities as determined by Section Curators and the Head Curator.

- Responsibility for volunteers will be delegated to a 'host' as appropriate, (e.g., Section Curator, Collection Manager, or Head Curator).

- Volunteers will receive all necessary training to enable them to perform their duties. The extent of training will be determined by the volunteer's role within the Collection.

- Volunteers must be inducted into NZAC facilities and fieldwork procedures as required.

- Volunteer access to the NZAC will be limited to specific days and times.

- The contribution and standard of work of volunteers will be actively monitored.

- $\quad$ Authority to continue or revoke the volunteer status of an individual rests with the Head Curator.

Volunteers provide a service that is of their own free will and without financial payment.

\section{Staff/Visitors leaving}

To ensure the safety of specimens, assign appropriate IP, and as a professional courtesy; retiring NZAC staff, or those leaving the NZAC, will brief the Head Curator and Collection Manager on all curatorial issues and the whereabouts of species and documentation (e.g., notebooks, photographs, files, etc.) relating to parts of the collection for which they have had responsibility, and must:

- $\quad$ Return loaned material that belongs to other institutions.

- Recall any overdue loans to the NZAC.

- Pass documentation regarding current and overdue loans, and loans belonging to other institutions, to the Head Curator.

- Ensure research and collection documentation that is to be archived in the NZAC is appropriately boxed, labelled, and has been sorted to remove personal and irrelevant documents.

- Ensure that specimens and material worked on is either reintegrated into collection or collection staff are made aware of material.

- Specimen metadata (e.g., images, sequence reference numbers, updated determination information) is provided so that specimen records can be updated.

Documentation from retiring NZAC staff, or those leaving the NZAC, will be passed onto the Head Curator, for them to pass onto a successor, if/when one has been appointed. 


\section{Conflicts of interest}

Other MWLR staff, research associates, and visitors to the NZAC shall

- Not use their connection to the NZAC to promote personal collecting, or for commercial gain.

- Declare any potential conflicts of interest to the Head Curator before gaining access to or carrying out work in the NZAC.

To avoid any possible conflict of interest in their activities as collectors, NZAC staff may not form or expand personal collections of invertebrate groups that fall within the remit of the NZAC. Personal collections formed before a staff member joined the NZAC may be retained, but objects and specimens need to be specifically declared in writing, and the Head Curator must be consulted before disposing of such a collection.

Specimens, samples, and equipment left in the NZAC facilities by visitors will be considered abandoned and subject to NZAC policy and procedures.

\section{Goals and objectives}

The below sections outline the vision, purpose and four long-term goals of the NZAC, and also the objectives to be completed over the next five years (July 2021-June 2026). Several objectives encompass work activities that are needed to address gaps or shortcomings in the current policy (e.g., development of a MTA, new procedures for use of specimens via loans, etc.). The next steps are to undertake internal workshops and prepare workplans for each objective, including milestones, resources, and timelines.

Vision: The NZAC is managed to the highest international standards, connected through a global infrastructure, and provides high quality, authoritative, and trusted information in a timely and flexible manner.

Purpose: To act as a long-term custodian of specimens, data, and information associated with terrestrial invertebrates, and to make these available to support and enable nationally important science outcomes to improve our understanding of the natural world.

The NZAC has four long-term goals:

1. Protect \& Preserve. Ensure the physical environment of the collections, the specimens, and the associated data are maintained to the highest international standards to maximise their long-term preservation and scientific value

2. Maintain \& Enrich. Maintain and enrich a comprehensive and scientifically based collection that is representative of the indigenous and exotic biota present in New Zealand and its offshore territories, including important voucher collections

3. Share \& Connect. Make specimens and associated data easily accessible, to facilitate their usefulness for outreach, diagnostics, and research 
4. Integrity \& Partnerships. Build on our foundation as a trusted collection through commitment to data quality excellence and by developing partnerships both nationally and internationally.

Goal 1. Protect \& Preserve - Ensure the physical environment of the collections, the specimens, and the associated data are maintained to the highest international standards to maximise their long-term preservation and scientific value.

Objective 1. Develop an emergency preparedness plan that includes an updated assessment of emergency planning and response options. Emergency preparedness is a process to reduce risks to the collection through assessment, planning, training, and ongoing preventive efforts. Recent disasters (e.g., fires) in natural science collections overseas have highlighted the importance of emergency preparedness. Covid-19 restrictions on site access and collection maintenance and the frequency of natural hazards in New Zealand (earthquakes), expedites the need for updated assessment and an emergency preparedness plan.

Objective 2. Upgrade the physical storage and complete labelling, databasing, and imaging of holotypes. Type specimens are the most scientifically valuable specimens. The NZAC holds over 4000 holotype specimens for a range of arthropod and nematode groups. Having images of these specimens (often old and fragile) reduces the need for physical loans and minimises risk of damage. The outcome of this objective will ensure these specimens are protected to modern standards, and information and images are available to enhance research.

Objective 3. Complete development of a new Material Transfer Agreement (MTA). A Material Transfer Agreement (MTA) is a contract that governs the transfer of research materials (e.g., biological specimens and samples) between two organizations or parties when the recipient intends to use materials for their own research purposes. This objective will ensure best practice systems are in place in the NZAC for permissions to hold, access, and use material.

Objective 4. Review and update loans policy and procedures to meet international best practice standards. Researchers frequently access specimens via the loan of specimens, especially for taxonomic revisions. There is a duty of care to ensure the specimens on loan are safeguarded and their associated data (e.g., DNA, images) is obtained and used appropriately. This objective will update procedures and documentation associated with the physical loans of specimens, that are either sent by, or received by, the NZAC.

Objective 5. Develop decision support systems and workflows for important curatorial activities. Well-developed workflows allow important curatorial activities to be conducted effectively and efficiently. This objective will develop decision support systems (such as decision trees embedded in procedures) to guide activities around incoming 
material, assessment of bulk samples, new taxonomic names, and the attribution of specimens.

Objective 6. Conduct an audit of major curatorial activities in the fluid collection stores. Samples and specimens held in fluid (e.g., ethanol) make up a high proportion of the NZAC holdings. This objective will audit current activities to help future planning; assess space to incorporate current and future holdings; develop a register of 'bulk samples'; and improve environmental conditions.

Goal 2. Maintain \& Enrich - Maintain and enrich a comprehensive and scientifically based collection that is representative of the indigenous and exotic biota present in New Zealand and its offshore territories, including important voucher collections.

Objective 7. Complete a collection wide inventory of holdings and curation status. The NZAC has a broad range of specimen types and holdings but more in-depth information, and at a higher resolution, is required. This objective will facilitate a collectionwide inventory of order and family level holdings and an assessment of curation status via a Collection Health Index (McGinley 1993) to inform future planning.

Objective 8. Provide rapid entry of newly published taxonomic names. Taxonomic names are a fundamental basic layer for managing collections and their databases. Names are also vital for subsequent research and feed into a growing global biodiversity cyberinfrastructure. The NZAC is a key provider of taxonomic names for New Zealand invertebrates and this objective will develop workflows so that the entry of newly published taxonomic names are rapidly available through online portals (e.g. NZOR, the New Zealand Organisms Register).

Objective 9. Undertake a gap analysis to prioritise the capture images for specieslevel diagnostics. Images are an important tool for diagnostics and the identification of taxa. This objective will undertake a gap analysis to prioritise invertebrate taxa for imaging to enable diagnostics and research for biosecurity and biodiversity, and als oassess future technologies (e.g., machine learning) for utilising images for mass digitisation and species identification.

Objective 10. Develop a DNA barcoding checklist. DNA is a vital tool for diagnostics and the identification of taxa. The NZAC aims to have a 'DNA barcode' for each terrestrial invertebrate species present in NZ. This objective will perform a gap analysis, create a checklist for prioritisation, and then perform targeted sequencing of invertebrate taxa in New Zealand.

Objective 11. Update taxonomic information and specimen holdings associated with vouchers of biological control agents. The NZAC is a repository for many important voucher specimens spanning almost a century of the intentional introductions of biological control agents into New Zealand. This objective will re-curate these specimens and capture their host associations and linkages. 


\section{Goal 3. Share \& Connect - Make specimens and associated data easily accessible, to facilitate their usefulness for outreach, diagnostics, and research}

Objective 12. Provide physical loans to researchers upon request. Loans of specimens are an important activity in collections as they provide an essential resource for researchers undertaking taxonomic revisions. This objective will implement new processes to meet new international shipping requirements and meet the KPI of the funding contract: 'ninety percent of loan requests are responded to within 2 weeks'.

Objective 13. Increase rate of primary data capture. Digitisation of incoming acquisitions and existing (historic) collection holdings is a key strategic focus for the NZAC enabling a wide range of biodiversity and biosecurity research to be undertaken. This objective will continue to develop the overall NZAC digitisation plan by: progessing digitisation of specific 'components' of collection holdings; having workflows so that objects are 'born-digital'; and upgrading the CMS to allow management of 'collection events'. This objective will meet a KPI of the funding contract: 'more than 7,000 specimens are accessioned per year'.

Objective 14. Identify, clean, and upload legacy datasets. Publicly sharing specimen records via the MWLR data portal and via global aggregators such as GBIF increases the discoverability of specimens for research. It also enables re-use of historical datasets by new users to answer new questions. This objective will review legacy datasets that are not yet publicly available. The datasets will be cleaned, configured to modern data standards, and uploaded to our CMS.

Objective 15. Document the interactions and linkages between the NZAC and the global research community. The use and impact of natural science collections has become a key discussion topic internationally. Attribution is an increasingly important part of demonstrating the contributions of workers to natural history collections and tracking how and where specimens are being used in research. Attribution includes linking the workers who collect and identify specimens (e.g., via Bionomia), the use of images and DNA sequences, and linking specimen records to the publication of scientific outputs and datasets. This objective will increase the number of linked records with associated research (e.g., publications, sequences, and media).

Objective 16. Verify and validate georeferences for standard collecting localities. Georeferenced locality information is of fundamental importance to many research studies that require species distribution data (e.g., the range of a threatened species, the distribution of an invasive species, etc.). Currently $60 \%$ of NZAC records have georeferences. This objective will refine georeferencing protocols, improve the accuracy of current georeferenced locality records, and increase the overall number of georeferenced specimen records within the dataset.

Objective 17. Develop one case study that makes the Pacific Holdings more accessible. The NZAC is a repository for $>150,000$ specimens from a wide range of 
Pacific Island Countries and Territories. However, most specimens are not digitised and are therefore inaccessible to users based within the Pacific. This objective will increase the accessibility of these holdings by digitisation, particularly with respect to taxonomic names, georeferencing, and imaging of specimens.

\section{Goal 4. Integrity \& Partnerships - Build on our foundation as a trusted collection through commitment to data quality excellence and by developing partnerships both nationally and internationally}

Objective 18. Extend the volunteer program through creation of dedicated projects and training. Volunteers can play an important role in collection management activities through the collective contribution of time and capacity beyond that supported by staff. This objective will extend the current basic volunteer program by developing training tools and setting up dedicated work programs and projects in curation and databasing.

Objective 19. Develop stronger partnerships that generate high quality samples and metadata. New acquisitions from external parties are a fundamental part of collection growth but often samples and their associated data do not arrive in the format required for efficient integration into NZAC. In other cases, opportunities to obtain useful material are missed because external parties do not realise the material would be valuable. Opportunities will be proactively sought to build mutually beneficial partnerships with iwi, researchers, and land managers to ensure that high quality sample material and metadata can be readily integrated into the collection. In turn this will create a better resource for our partners and endusers.

Objective 20. Work with Māori partners on options for integrating biocultural labels. Biocultural labels are increasingly acknowledged as an useful approach for recognising the importance of digital data for indigenous people. This objective will explore options to integrate such labels systems with the NZAC dataset through our CMS.

Objective 21. Capture historic permit information and reuse conditions. The NZAC has a responsibility to ensure that collection objects are legally obtained, held, and that use of specimens and data meets reuse conditions or restrictions. Linking permit information and reuse conditions to specimen records will improve the visibility of conditions and ensure that the NZAC remains a trusted collection.

Objective 22. Undertake an audit of the digitised specimen dataset. Data quality has become an important international issue for natural science collections. Improving data quality will promote the further use of records from collections. In this objective, a data quality audit of our specimen dataset will be undertaken to improve future data capture, transcription, and digitsation workflows. 


\section{Acknowledgements}

Thanks to Austin Mast and David Jennings for the opportunity to participate in the online workshops on 'Strategic Planning for Biodiversity Collections Course' held Oct-Dec 2020 and organised by iDigBio (Integrated Digitised Biocollections), an NSF funded program (attended by ST).

\section{Author contributions}

DW and ST developed, prioritised, and wrote the goals, objectives, and policy.

\section{Conflicts of interest}

The authors declare no conflicts of interest

\section{References}

- $\quad$ Committee on Biological Collections (2020) Biological Collections: Ensuring Critical Research and Education for the 21st Century. National Academies Press, Washington DC. [In English]. https://doi.org/10.17226/25592

- $\quad$ Crosby TK, Dugdale JS, Watt JC (1998) Area codes for recording specimen localities in the New Zealand subregion. New Zealand Journal of Zoology 25: 175-183. [In English]. https://doi.org/10.1080/03014223.1998.9518148

- Hodgson P (2008) Direction to the Foundation for Research, Science and Technology for Backbone Research and Science Scheme. New Zealand Gazette 162 (4209): 4255. [In English].

- Lendemer J, Thiers B, Monfils AK, Zaspel J, Ellwood ER, Bentley A, LeVan K, Bates J, Jennings D, Contreras D, Lagomarsino L, Mabee P, Ford LS, Guralnick R, Gropp RE, Revelez M, Cobb N, Seltmann K, Aime MC (2019) The Extended Specimen Network: A Strategy to Enhance US Biodiversity Collections, Promote Research and Education. BioScience 70 (1): 23-30. https://doi.org/10.1093/biosci/biz140

- McGinley R (1993) Where's the management in collection management? Planning for Improved Care, Greater Use and Growth of Collections. International Symposium and First World Congress on the preservation and conservation of Natural History Collections 3. 309-333 pp. [In English].

- Mietchen D, Penev L, Georgiev T, Ovcharova B, Kostadinova I (2021) Open science in practice: 300 published research ideas and outcomes illustrate how RIO Journal facilitates engagement with the research process. Research Ideas and Outcomes 7 (e68595). [In English]. https://doi.org/10.3897/rio.7.e68595

- Miller S, Barrow L, EhIman S, Goodheart J, Greiman S, Lutz H, Misiewicz T, Smith S, Tan M, Thawley C, Cook J, Light J (2020) Building Natural History Collections for the Twenty-First Century and Beyond. BioScience 70 (8): 674-687. [In English]. https://doi.org/10.1093/biosci/biaa069 
- $\quad$ NZAC-GBIF (2021) New Zealand Arthropod Collection (NZAC). Version 1.243.

Landcare Research. Occurrence dataset https://doi.org/10.15468//rgzz9.

https://www.gbif.org/dataset/6e4b215e-9019-4934-8433-65d80a35c230.

Accessed on: 2021-4-07.

- $\quad$ SPHNC. (2021) Guidelines for the Care of Natural History Collections.

https://cool.culturalheritage.org/byorg/spnhc/spnhc1.html. Accessed on: 2021-6-02.

- Väinölä R, Kaila L, Mattila J, Sihvonen P, Hyvärinen M, Schulman L, Juslén A (2020) Invertebrate collections policy of the Finnish Museum of Natural History. Research Ideas and Outcomes 6 https://doi.org/10.3897/rio.6.e62373

- Walker AK, Crosby TK (1988) The Preparation and Curation of Insects. DSIR, Wellington, 91 pp. [In English]. 